\title{
Digital Proficiency and Psychological Well-Being in Online Learning: Experiences of First-Generation College Students and Their Peers
}

\author{
Xuefei (Nancy) Deng ${ }^{1, *(D)}$ and Zheng Yang ${ }^{2}$ \\ 1 Department of Information Systems and Operations Management, California State University \\ Dominguez Hills, Carson, CA 90747, USA \\ 2 Department of Public Administration, California State University Dominguez Hills, Carson, CA 90747, USA; \\ zyang@csudh.edu \\ * Correspondence: ndeng@csudh.edu
}

Citation: Deng, Xuefei (Nancy), and Zheng Yang. 2021. Digital Proficiency and Psychological Well-Being in Online Learning: Experiences of First-Generation College Students and Their Peers. Social Sciences 10: 192. https://doi.org/10.3390/ socsci10060192

Academic Editor: Nigel Parton

Received: 25 April 2021

Accepted: 20 May 2021

Published: 25 May 2021

Publisher's Note: MDPI stays neutral with regard to jurisdictional claims in published maps and institutional affiliations.

Copyright: (c) 2021 by the authors. Licensee MDPI, Basel, Switzerland. This article is an open access article distributed under the terms and conditions of the Creative Commons Attribution (CC BY) license (https:// creativecommons.org/licenses/by/ $4.0 /)$.

\begin{abstract}
The study examines the role of digital proficiency in relation to psychological well-being of a vulnerable population — first-generation college students (FGS) — and their counterparts, continuingeducation students, in online learning during the coronavirus pandemic (COVID-19). Informed by positive computing and FGS studies, this paper empirically tests a model of three key influencing factors by using a data sample $(n=309)$ collected from a minority-serving university in the U.S. in April 2020. Our data analysis confirms that FGS underperformed in digital proficiency, compared to their peers. Moreover, digital proficiency had a significant effect on individual psychological wellbeing, regardless of a student's generational status. Our paper contributes to the positive computing research by empirically demonstrating the association between users' technology competence and psychological well-being. Practically, our findings highlight the importance of implementing educational programs and policies to promote the digital skills and well-being of underserved students such as FGS in college education.
\end{abstract}

Keywords: digital proficiency; psychological well-being; college students; information and communication technology; quantitative analysis; COVID-19

\section{Introduction}

Information and communication technology (ICT) has transformed work processes and user performance in various organizational settings. However, little is known about the impacts of ICT on a vulnerable population, first-generation college students (FGS), in the online learning environment. Higher education institutions continue to face the challenges associated with enhancing the academic persistence and success of first-generation students in college. FGS are students who enroll in postsecondary education and whose parents do not have any post-secondary education experience (Redford and Mulvaney Hoyer 2017). They have shown different characteristics from their counterparts, continuingeducation students (CGS): FGS are more likely to be low-income, single mothers who often enroll at two-year institutions and experience lower SES (social-economic status), academic and social integration in college (Nunez and Cuccaro-Alamin 1998). Most FGS struggle financially and have to work full-time while attending college part-time (Engle and Tinto 2008). All the factors are negatively associated with FGS college persistence. This population of college students faces economic, cultural, and social barriers in their transition to college and navigation throughout their college years.

This vulnerable population of college students faced new risks and unprecedented learning challenges in 2020. The year 2020 has brought millions of people worldwide personal and professional challenges and has witnessed the world's biggest health crisisthe coronavirus pandemic (COVID-19). Starting in December 2019, from a city located in 
central China, the dangerous infectious coronavirus was officially declared a worldwide pandemic by the World Health Organization (WHO) on March 11th 2020 (WHO 2020). By the end of 2020, COVID-19 had infected more than 87 million people and taken 1.8 million lives worldwide, according to Johns Hopkins University's COVID-19 dashboard (Accessed on 31 December 2020; https: / / coronavirus.jhu.edu/map.html).

In addition to the alarming death tolls, the coronavirus pandemic has devastated the economy, causing 20.5 million workers in the U.S. to be out of jobs in April 2020 and driving the U.S. unemployment rate to 14.7 percent, the highest in U.S. history (Chaney and Morath 2020). The pandemic has also severely impacted people's mental health. According to McKinsey's COVID-19 National Consumer Survey in the U.S. during 27-29 March 2020, $80 \%$ of the total 1062 respondents reported medium or high stress, and this widespread distress was found to be exacerbating further among those who suffered from reduced income or job loss due to COVID-19 (Coe and Enomoto 2020). Among the populations suffering from the health, economic, and mental risks arising during COVID-19, African American and Hispanic/Latino minority communities experienced disproportionally high risk (CDC 2020). First-generation college students mostly come from African American and Hispanic/Latino communities. Thus, on top of the economic, cultural, and social barriers that they had already encountered prior to COVID-19, FGS found themselves subject to new risks as their college education was disrupted by the unprecedented pandemic.

The coronavirus pandemic has forced higher education institutions around the world to adopt technology-mediated teaching such that universities in the U.S. and other regions of the world have relied on the Internet platform as the primary delivery mode of communication and instructions. For students taking classes online, their competence in using technologies for online learning platforms has become a critical success factor ( $\mathrm{Ng}$ 2012). Meanwhile, research on the academic success of postsecondary students has paid attention to the important role of students' psychological well-being (PWB) (Bewick et al. 2010; Everett 2017; Na et al. 2017). Prior research has suggested that increasing institutional and classroom supports for student learning enhances students' well-being, which is critical for their academic success (Bewick et al. 2010; Everett 2017; Hung et al. 2015; Johnson et al. 2005). On virtual learning platforms, a critical factor affecting PWB is individual proficiency in online technologies. Understanding the role of information technology proficiency (referred to as "digital proficiency" in the paper) on the psychological well-being of FGS is helpful for educational institutions to better support FGS not only academically but also mentally during the crisis.

This study examines the relationship between digital proficiency and psychological well-being and compares the experiences of FGS and those of their peers, CGS. In particular, this study answers two questions: (1) How does digital proficiency explain the psychological well-being of first-generation college students and their counterparts? (2) How do individual background factors explain the psychological well-being of first-generation college students and their counterparts?

To answer the research questions, we draw upon research on positive computing (Calvo and Peters 2014, 2015) and psychological well-being (Chen and Li 2017; Diener and Ryan 2009). We define psychological well-being as an individual feeling about their quality of life, personal growth, and positive relations, consistent with prior research (Chen and Li 2017; Diener and Ryan 2009) and propose a model of three key factors contributing to college students' psychological well-being. To empirically test the model, we collected survey data from 309 college students (including 200 first-generation students) from a four-year urban, public university located in the western United States during the first two weeks of its alternative instruction (i.e., distance learning) in late March of 2020 due to the COVID-19 disruption. Our data analysis shows that FGS underperformed in digital proficiency, compared to CGS. Moreover, a student's digital proficiency had a significant effect on his/her psychological well-being, regardless of the student's generational status (FGS or CGS). In addition, employment status and caregiving responsibility were found to be related differently to the psychological well-being of FGS and CGS. 
The remainder of the paper is organized as follows: Section 2 reviews literature on FGS, digital proficiency, and psychological well-being, and develops hypotheses. Section 3 describes the method used for data collection and analysis, followed by the presentation of results in Section 4. Section 5 discusses the results, research contributions, and practical implications for online education. The paper concludes in Section 6 with suggestions for future research.

\section{Literature Review}

\subsection{First-Generation College Students and Digital Proficiency}

In this study, we define first-generation students as the students who enroll in postsecondary education and whose parents do not have a bachelor's degree. By contrast, continuing-generation students are the students enrolling in postsecondary education and having at least one parent with a bachelor's degree. This definition is consistent with prior research (Garriott and Nisle 2018; Redford and Mulvaney Hoyer 2017). The comparison between FGS and their peers, CGS, has been striking, especially in their college persistence and success. FGS go into their college life with no one (e.g., parents) leading the way nor having any pre-exposure to what to expect as a new college student. Many FGS do not understand the program requirements or academic culture; they often fail to identify support systems. Research has found that FGS are twice as likely to leave college without a degree (Chen and Carroll 2005). Redford and Mulvaney Hoyer (2017) studied a nationally representative sample of high school sophomores in the U.S. between 2002 and 2012. Their study revealed a big gap in their college graduation rate: the percentage of FGS who had obtained a bachelor's degree was much lower than that of CGS, at $20 \%$ and $42 \%$ respectively.

The gap in college persistence between FGS and CGS has plagued post-secondary educational institutions. Prior studies have examined major obstacles to the college persistence and success of FGS. For example, family obligations and personal circumstances, such as health problems and emotionally stressful events, have been found to exert a negative effect on the college success of FGS (Burrus et al. 2013). Moreover, a dearth of on-campus connections has become a significant stressor, especially when FGS face the challenge of effectively navigating the college environment (Schwartz et al. 2018). Lohfink and Paulsen (2005) found that three background variables-being Hispanic, low-income, and femalewere negatively associated with FGS persistence from the first year to the second year in college, suggesting that race and ethnicity interacted with parental education to impact the persistence behaviors of FGS.

Digital technologies have facilitated and enabled the learning process, allowing both synchronous and asynchronous deliveries of information to learners who could not attend classes in person (Appana 2008). With the increasing adoption of digital technologies in college education, students' ability to utilize digital technologies has been found to facilitate their learning activities and affect their learning outcomes. Such technologies for educational purposes include desktops, mobile devices (e.g., laptops, tablets, smartphones), communication and collaborative tools, and a variety of software packages for learning. Prior studies on digital divide have shown that young people from low-income households had not overcome their relative disadvantages in terms of accessing and using the Internet and digital technologies (Livingstone and Helsper 2007). As FGS are mostly coming from low-income families (Engle and Tinto 2008; Nunez and Cuccaro-Alamin 1998), it is likely that FGS do not reach the same proficient level of technology use, compared to CGS. To extend the conceptualization of digital literacy in the prior study ( $\mathrm{Ng} 2012)$, we define digital proficiency as individual ability to utilize online course management systems such as Blackboard and interactive video/audio conference tools (i.e., Zoom) to accomplish online, virtual education in the context of online learning platforms. Based on the above reasonings, we predict: 
Hypothesis 1 (H1). Digital proficiency of first-generation college students is lower than that of continuing-education college students.

\subsection{Digital Proficiency and Psychological Well-Being}

Psychological well-being is a multifaceted construct: it is influenced by several factors. The self-determination theory by Ryan and Deci (2000) provides a comprehensive account of intrinsic motivation and its role in the development of psychological well-being. According to this model, in order to foster individual well-being and health, three basic needs must be satisfied: autonomy, competence, and relatedness. Autonomy refers to the urge to be causal and self-governing agents, who act in harmony with their integrated selves. Competence refers to the experience of behavior as effectively enacted. Finally, relatedness is a universal need to interact with other human beings, be connected, and experience caring for others.

Research findings on the relationship between digital technology use and psychological well-being have been mixed (Chen and Li 2017; Van den Eijnden et al. 2008). Human-computer interaction ( $\mathrm{HCI}$ ) scholars have advocated for the positive role of computing in everyday life. They premise that, since ICT has become an integral part of our daily life, it could be designed to enhance users' psychological well-being, in addition to achieving the goals of usability and productivity (Gaggioli et al. 2017). "Positive Computing" is a new approach of technology design that incorporates psychological well-being into everyday software design practices (Calvo and Peters 2014, 2015). Scholars have proposed various frameworks on how technology design supports or undermines the basic psychological needs of human users. One such model is called Motivation, Engagement and Thriving in User Experience (METUX), which details the important phases of user-system interactions that increase user motivation and engagement, and ultimately improve individual well-being (Peters et al. 2018). According to this model, well-being can be promoted during the three key phases of users' engagement with technology, including interaction with the interface, engagement with technology-specific tasks, and conduct of technology-supported behaviors.

Competence is considered as one basic need to be satisfied for well-being: satisfying the competence need has become essential for individual psychological growth (Ryan and Deci 2000). In online learning contexts, one's ability to interact with the digital technologies (Blackboard, Zoom) will enhance one's effective behavior in accomplishing individual goals. Virtual learning platforms (e.g., Blackboard, Moodle) facilitate active learning and student-centered pedagogy that goes beyond didactic teaching designs; such active learning and student-centered pedagogy requires students to be proficient in using digital technologies in order to fully engage, employ, and benefit from the pedagogy. Previous research has demonstrated numerous positive outcomes associated with active learning pedagogy, including improving students' learning attitudes, strengthening motivation and relevance, and enhancing student engagement and collaboration (Drinkwater et al. 2014; Khan et al. 2017). However, benefiting from active learning in a virtual learning context requires digital literacy and proficiency, which may not be a competency equally equipped across students. Lower digital proficiency in virtual learning contexts may hinder students from adapting to new learning contexts, achieving satisfactory learning results, and developing learning autonomy (Shopova 2014; Tang and Chaw 2016; Ting 2015), which can result in lower psychological well-being. Therefore, we predict:

\section{Hypothesis 2 (H2). Digital proficiency is positively related to psychological well-being.}

Yet, the effect of digital proficiency on PWB may differ by the two college student cohorts, FGS and CGS. Active engagement with college experience has been a success factor contributing to the college persistence of FGS. For example, Lohfink and Paulsen (2005) have shown a significant, positive impact of FGS in-college experiences on their first-to-second-year persistence, including their integration into campus student clubs and activities, satisfaction with their social lives, and their first-year GPA (Grade Point 
Average). Similarly, Dumais and Ward (2010) have highlighted the importance of "strategic interactions" with teachers and other gatekeepers for the persistence and success rates of FGS. Campus clubs and student engagement events, as well as support services such as instructor office hours, peer mentors, and tutoring services, are all considered institutional support. First-generation college students' access to the institutional supports was found to be helpful in reducing their stress and improving their perceived academic goal progress (Garriott and Nisle 2018). Recently, Schwartz and colleagues (2018) have studied the effects of skill development and attitude invention program on FGS and provided evidence to demonstrate the positive effect of students' help-seeking behaviors from peers and relationship-building with instructors on their successful transition during the first year, including higher GPAs at the end of the year. These studies have shown that developing a sense of social support and engagement in and outside the classroom are critical factors addressing high attrition rates and increasing the academic performance of FGS.

During COVID-19, such campus connections and engagement enabled by digital platforms have become more important, especially for FGS who lack financial and educational resources to persist in college. In challenging times such as COVID-19, the more proficient FGS students are with the course management systems such as Blackboard and teleconferencing tools such as Zoom, the better they are equipped to engage with their instructors and peers and achieve their online learning tasks, increasing their psychological well-being (Peters et al. 2018). As such, during the college transition from in-person to online instruction modality due to COVID-19, it has become essential for FGS to develop and apply digital skills to navigate the online learning environments. These reasonings have led us to predict:

Hypothesis 3 (H3). The first-generation student status moderates the relationship between digital proficiency and psychological well-being; the effect of digital proficiency on psychological well-being is stronger on FGS than on CGS.

\subsection{Individual Background and Psychological Well-Being}

During the challenging times of COVID-19, the determinants of students' psychological well-being in the online learning environment should not be limited to their proficiency with the technology platforms. Rather, factors associated with their social-economic status, family, educational institution, and external environment are all important components. For example, a prior study (Gui et al. 2017) highlights that users' psychological well-being is not only related to individual skills and technology proficiency; rather, it is associated with social norms and user expectations for technology.

We examine two key variables that have emerged as critical during the pandemic: employment status and caregiving responsibilities. First, employment status is an important factor contributing to individual well-being during COVID-19. Prior studies have shown that unemployment has a consistent and unequivocally negative impact on individual subjective well-being (Clark 2010; Diener and Ryan 2009). With the national lockdowns and businesses closing (i.e., restaurants, bars, barbers, salons) in response to COVID-19, millions of workers have lost their jobs. For example, in April 2020, the COVID-19 crisis drove the U.S. unemployment rate to an alarming rate of 14.7 percent, the highest in U.S. history (Chaney and Morath 2020). Under this circumstance, being employed allowed one to provides financial stability to one's family, which is likely to positively affect one's psychological well-being. Therefore, we predict:

Hypothesis $4 \mathbf{a}$ (H4a). The employment status of being employed is positively related to psychological well-being.

Alternatively, in the college learning context, it would be equally, if not more, plausible that being employed might become a burden to a student's time management, causing work and study conflicts, and increasing the student's anxiety. Working while studying was found to be related to students' engagement and well-being: more time demands from 
college and fewer psychological rewards from employment were associated with more work-university conflict, causing students' negative feelings toward the university (Creed et al. 2015). Similarly, as shown in a prior study of adult learners (Kohler Giancola et al. 2009), managing the balance between work and academic study is difficult, and workuniversity conflict has emerged as a key stressor for adult students. Due to this reasoning, we predict an alternative hypothesis below. We will test the competing hypotheses (H4a and $\mathrm{H} 4 \mathrm{~b}$ ) by using our data sample.

Hypothesis $\mathbf{4 b} \mathbf{( H 4 b ) . ~ T h e ~ e m p l o y m e n t ~ s t a t u s ~ o f ~ b e i n g ~ e m p l o y e d ~ i s ~ n e g a t i v e l y ~ r e l a t e d ~ t o ~ p s y c h o - ~}$ logical well-being.

In addition to employment status, another important influencing factor is the degree of caregiving responsibilities. The experience of caring for others is considered as one basic need for fostering well-being and health (Ryan and Deci 2000). Similarly, individual orientation to others, such as being a caring, compassionate person and having good relationships, is perceived as an important attribute to affect well-being (Ryff 1989). When a person spends time and effort to care for a family member, such as a baby or an elder, the individual demonstrates his/her compassion to family, contributing to a supportive family network. Having caregiving responsibilities often indicates a person's strong social support network and social relations, which decrease one's psychological stress, anxiety, sense of loneliness and sense of uncertainty during a time of crisis (Schwartz et al. 2018). According to education research, such family investment of nonmaterial resources is a valuable source of perceived social capital, which directly and positively influences students' psychological well-being and academic motivation (Emadpoor et al. 2016). This experience has become much needed and appreciated during COVID-19 when family members were all required to stay at home or shelter in place. Moreover, giving care to others may move the attention of a person from their own concerns onto others' concerns, which can lead to positive psychological indicators (Yang 2021). Based on these reasonings, we predict:

Hypothesis 5a (H5a). The degree of caregiving responsibility is positively related to psychological well-being.

Alternatively, as with the employment status predicted above (in $\mathrm{H} 4 \mathrm{a}$ and $\mathrm{H} 4 \mathrm{~b}$ ), a caregiving responsibility might become a burden to a student's time management, becoming an obstacle to their college success and increasing the student's anxiety. For example, according to a study of adult learners (Kohler Giancola et al. 2009), school-family conflict has emerged as a key stressor for the students, making it difficult for them to balance the needs of taking care of families and persisting in their academic study. Due to this reasoning, we predict the alternative hypothesis below:

Hypothesis $\mathbf{5 b} \mathbf{b}(\mathbf{H} 5 \mathbf{b})$. The degree of caregiving responsibility is negatively related to psychological well-being.

\section{Research Methodology}

\subsection{Research Site and Data Collection}

The participants of this study were undergraduate and graduate students at a Business College at a four-year urban, public university on the west coast of the United States. The university is known as a Hispanic-serving institution with $60 \%$ of students being Hispanic or Latino, 15\% Black or African American, 11\% White, 11\% Asian and others, as of Spring 2018. In addition, $54 \%$ of its student body are first-generation, the first in their family to attend college. Given the diversity of the student background, this university became an ideal research site for us to study the well-being and digital proficiency of FGS in online learning during the COVID-19 pandemic.

Prior to COVID-19, the campus offered three modalities of classes: in-person (oncampus), online, and hybrid, with the in-person/on-campus classes enrolling the majority 
of the students. The university had utilized and supported the learning platform "Blackboard" as the main web-based course management system. On 11 March 2020, as the situation of COVID-19 deteriorated in the United States, the university announced its decision to suspend all on-campus classes and to transform in-person teaching into alternative, online instruction. On 23 March, the university formally started its "alternative instruction" and continued the mode till the end of the 2020 spring semester.

Our survey invitation was sent to student participants during the first week after campus alternative instruction started. Six professors from four departments of the Business College voluntarily distributed the survey invitation and link to their students through class announcements, followed by one reminder email. The 12 min survey was deployed via SurveyMonkey, in which participants were asked about their concerns with COVID-19, and their views towards technology readiness, learning needs, and barriers of learning under the alternative instruction mode. Participants were also asked to assess their psychological well-being in the survey. For example, survey questions include "How concerned are you about the coronavirus (COVID-19) spread in the U.S. now?" "Do you have a computer at home?" "Do you have Internet Access at home for using the Blackboard?" "What are the major barriers for you to continue the college classes via the alternative instruction mode (such as distance learning) during the remaining weeks of the semester? Please explain."

The online survey remained open for the first two weeks after the start of alternative instruction and closed on 10 April 2020. Among all the 500 students who were invited to participate in the survey, a total of 309 students completed the online survey, resulting in a response rate of $61.8 \%$.

\subsection{Variables and Measurement}

Psychological well-being was measured by asking participants to rate on five items based on their college experience on a 5-point scale from "1—Disagree Strongly" to "5Agree Strongly. The five items are: (1) I am engaged and interested in my daily learning activities at the university; (2) I actively contribute to the happiness and well-being of others at the university; (3) My social relationships at the university are supportive and rewarding; (4) I am competent and capable in the learning activities that are important to me at the university and (5) I am optimistic about my future after graduating from the university. These five items measure students' level of engagement, contribution, social relationships, competency, and optimism in the university context. The measures were adapted from Diener and Ryan (2009), which has demonstrated a good level of reliability. Consistent with prior research (Chen and Li 2017; Diener and Ryan 2009), our data show a good level of reliability for the measures (Cronbach Alpha $=0.850$ ). These items were then averaged to measure student psychological well-being, with a higher value indicating a greater level of psychological well-being.

Digital proficiency was measured by averaging two items to assess students' proficiency with using ICT tools on a 4-point Likert scale from " 1 -Not Proficient" to " 4 -Very Proficient". The first item assessed their proficiency in "Web-based course management system, e.g., Blackboard"; the second assessed proficiency in "Internet video and audio call services, e.g., Zoom" (Ng 2012).

Employed has two values, with 0-not employed, and 1-employed (including both part-time and full-time employment).

Caregiving responsibilities was conceptualized as the categories of different family caregiving responsibilities. The survey question asked participants to identify what caregiving responsibilities they have taken during COVID-19 at home (i.e., "none", "taking care of children", "taking care of elderly parent(s)", "taking care of grandparents", "other"). Participants were asked to check all that apply. Then the measure was created by counting the types of caregiving responsibilities that the participants have checked, where a higher value indicated more caregiving responsibilities. 
Satisfaction with the university was measured by asking students to rate how satisfied they were with the university's academic programs overall on a 5-point Likert scale from " 1 -Very dissatisfied" to "5-Very satisfied."

Concern intensity with COVID-19 measured how concerned participants perceived themselves to be about the COVID-19 spread in the U.S. at the time of the survey, based on a 4-point Likert scale (1-Not concerned at all; 4-Very concerned).

In addition, our control variables included several demographic variables that were discussed by existing literature to be possibly relevant to college students' psychological well-being (Diener and Ryan 2009). "Age" was an interval variable measured by the self-reported age, and "married" (0—not married, 1-married) was measured and operationalized as a dichotomous variable.

\subsection{Data Analysis: Descriptive Statistics, Mean Comparison, and Correlations}

We first conducted a series of descriptive analyses to explore the frequencies of key variables and the assumptions of key tests. We then conducted mean comparisons, correlational analyses, and regression analyses to test our key hypotheses. The analytical software SPSS was utilized for data analysis. We used the "Split File" function in SPSS which enabled running the regressions separately for the two cohorts (FGS and CGS) of participants.

First, the descriptive analysis of our data sample shows that $91.9 \%$ of respondents are undergraduate students, with the majority being junior (45.6\%) and senior (38.4\%); $64.7 \%$ of our sample were FGS, while $35.5 \%$ were CGS. About $66.7 \%$ of the participants were employed full-time or part-time, and the remaining 33.3\% were full-time students only. The average age of participants was 26.6, with an average household income falling between Level 3 (\$35,000 to $\$ 49,999$ ) and Level 4 (\$50,000 to $\$ 74,999) ; 58.9 \%$ of participants identified themselves as Hispanic or Latino, 14.9\% as Asian or Pacific Islander, $12 \%$ as African American, 9.4\% as White, and 5.2\% others.

Next, we conducted a correlational analysis to explore the linear relationships between key variables. As reported in Table 1, digital proficiency is positively correlated with psychological well-being $(r=0.326, p=0.000)$. In addition, student age $(r=0.120$, $p=0.035)$ and satisfaction with the university academic programs $(\mathrm{r}=0.424, p=0.000)$ also positively correlated with psychological well-being. Interestingly, students' level of concern with COVID-19 is not significantly correlated with PWB. Similarly, employment status, caregiving responsibilities, gender, year in school, FGS status, and household income are not found to be significantly correlated with psychological well-being.

Table 1. Correlational analysis.

\begin{tabular}{|c|c|c|c|c|c|c|c|c|c|c|}
\hline & & 1 & 2 & 3 & 4 & 5 & 6 & 7 & 8 & 9 \\
\hline 1 & $\begin{array}{l}\text { Psychological } \\
\text { well-being }\end{array}$ & 1 & & & & & & & & \\
\hline 2 & Digital proficiency & $0.326^{* *}$ & 1 & & & & & & & \\
\hline 3 & Age & $0.120 *$ & 0.063 & 1 & & & & & & \\
\hline 4 & Employed & 0.025 & 0.023 & 0.122 * & 1 & & & & & \\
\hline 5 & $\begin{array}{l}\text { Caregiving } \\
\text { responsibilities }\end{array}$ & 0.034 & $-0.151^{* *}$ & $0.152^{* *}$ & 0.075 & 1 & & & & \\
\hline 6 & $\begin{array}{c}\text { Concern level } \\
\text { with COVID-19 }\end{array}$ & 0.019 & -0.049 & $0.11^{\wedge}$ & 0.038 & $0.235 * *$ & 1 & & & \\
\hline 7 & $\begin{array}{l}\text { Satisfaction with } \\
\text { university }\end{array}$ & $0.424^{* *}$ & 0.292 ** & 0.113 * & $0.113^{*}$ & 0.03 & 0.087 & 1 & & \\
\hline 8 & Gender & -0.023 & 0.011 & -0.1 & $-0.156^{* *}$ & $-0.148^{* *}$ & $-0.201^{* *}$ & $-0.094^{\wedge}$ & 1 & \\
\hline 9 & $\begin{array}{l}\text { First-generation } \\
\text { students }\end{array}$ & 0.035 & $-0.126^{*}$ & 0.043 & $0.139 *$ & 0.143 * & 0.093 & 0.038 & -0.086 & 1 \\
\hline
\end{tabular}


Particularly, the correlational analysis shows that students who have high digital proficiency are those who have fewer caregiving responsibilities $(\mathrm{r}=-0.151, p=0.008)$, higher overall satisfaction with university academic programs $(\mathrm{r}=0.292, p=0.000)$, and are CGS $(\mathrm{r}=-0.126, p=0.027)$. These findings align with the existing literature about FGS and key findings of students with digital proficiency.

We ran mean comparisons for the two samples (FGS and CGS) to test whether there are significant differences in the mean of key variables (Table 2 in the next section). Next, we conducted regression analyses on the two samples separately and presented the results for three different models in Table 3 in the next section.

Table 2. Descriptive statistics grouped by FGS and CGS.

\begin{tabular}{|c|c|c|c|c|c|c|c|c|c|c|c|c|}
\hline & \multicolumn{5}{|c|}{ FGS } & \multicolumn{5}{|c|}{ CGS } & \multicolumn{2}{|c|}{$\begin{array}{l}\text { ANOVA Mean } \\
\text { Comparison }\end{array}$} \\
\hline & $\mathbf{N}$ & Min & Max & Mean & $\begin{array}{l}\text { Std } \\
\text { Dev }\end{array}$ & $\mathbf{N}$ & Min & Max & Mean & $\begin{array}{l}\text { Std } \\
\text { Dev. }\end{array}$ & F & Sig. \\
\hline Age & 199 & 19 & 59 & 26.78 & 6.60 & 109 & 18 & 55 & 26.17 & 7.56 & 0.558 & 0.456 \\
\hline $\begin{array}{c}\text { Digital } \\
\text { proficiency }\end{array}$ & 200 & 1 & 4 & 3.27 & 0.67 & 109 & 2 & 4 & 3.44 & 0.56 & $4.952 *$ & 0.027 \\
\hline Employed & 200 & 0 & 1 & 0.72 & 0.453 & 109 & 0 & 1 & 0.58 & 0.496 & NA & NA \\
\hline $\begin{array}{l}\text { Caregiving } \\
\text { responsibilities }\end{array}$ & 199 & 0 & 3 & 0.62 & 0.69 & 109 & 0 & 3 & 0.42 & 0.63 & $6.346^{*}$ & 0.012 \\
\hline $\begin{array}{c}\text { Concern level } \\
\text { with COVID-19 }\end{array}$ & 200 & 1 & 4 & 3.21 & 0.84 & 109 & 1 & 4 & 3.05 & 0.83 & 2.702 & 0.101 \\
\hline $\begin{array}{l}\text { Household } \\
\text { income }\end{array}$ & 197 & 1 & 7 & 2.86 & 1.50 & 107 & 1 & 7 & 3.7 & 1.93 & $17.511^{* *}$ & 0.000 \\
\hline $\begin{array}{l}\text { Income lost due } \\
\text { to COVID-19 (\%) }\end{array}$ & 160 & 0 & 100 & 45.17 & 43.65 & 79 & 0 & 100 & 29.49 & 39.12 & 7.292 ** & 0.007 \\
\hline $\begin{array}{l}\text { Psychological } \\
\text { well-being }\end{array}$ & 199 & 1 & 5 & 3.92 & 0.81 & 109 & 2 & 5 & 3.87 & 0.69 & 0.376 & 0.540 \\
\hline $\begin{array}{c}\text { Satisfaction with } \\
\text { university }\end{array}$ & 200 & 2 & 5 & 3.89 & 0.83 & 109 & 2 & 5 & 3.83 & 0.78 & 0.441 & 0.507 \\
\hline
\end{tabular}

Note: ${ }^{* *} p<0.01,{ }^{*} p<0.05$

Table 3. Regression on psychological well-being (CGS).

\begin{tabular}{cccc}
\hline & CGS & & \\
\hline & $\begin{array}{c}\text { Model 1 } \\
\text { (Control Only) }\end{array}$ & $\begin{array}{c}\text { Model 2 } \\
\text { (Without Digital } \\
\text { Proficiency) }\end{array}$ & $\begin{array}{c}\text { Model 3 } \\
\text { (Full Model) }\end{array}$ \\
\hline Age & $0.155^{\wedge}$ & 0.126 & 0.094 \\
\hline Gender & 0.027 & 0.085 & 0.079 \\
\hline Concern level with COVID-19 & 0.054 & 0.049 & 0.042 \\
\hline Satisfaction with university & $0.389^{* *}$ & $0.365^{* *}$ & $0.262^{* *}$ \\
\hline Employed & & $0.196^{*}$ & $0.204^{* *}$ \\
\hline Caregiving responsibilities & & 0.127 & $0.148^{\wedge}$ \\
\hline Digital proficiency & & & $0.322^{* *}$ \\
\hline R-square (Adj R-square) & $0.201(0.170)$ & $0.255(0.212)$ & $0.347^{*}(0.301)$ \\
\hline F value & $6.521^{* *}$ & $5.832^{* *}$ & $7.657^{* *}$ \\
\hline
\end{tabular}

Note: Cell entries are standardized coefficients (ß). ${ }^{* *} p<0.01,{ }^{*} p<0.05,{ }^{\wedge} p<0.10$. 


\section{Results}

Hypothesis 1 predicts a significant difference between the digital proficiency of FGS and CGS. The results reported in Table 2 show the mean comparison results (ANOVA) for the two samples (FGS and CGS). The results indicate that, compared to CGS, FGS are significantly lower in digital proficiency $(\mathrm{F}=4.952, p=0.027)$, thus supporting Hypothesis 1 . In addition, the analysis shows that FGS are significantly higher in caregiving responsibilities $(\mathrm{F}=6.346, p=0.012)$, lower in household income $(\mathrm{F}=17.511, p=0.000)$, and higher in COVID-19-related income loss $(\mathrm{F}=7.292, p=007)$. These results are consistent with the previous FGS literature that emphasized the disadvantages of first-generation students in family responsibilities, financial resiliency, learning proficiency, and social resources (Burrus et al. 2013; Nunez and Cuccaro-Alamin 1998). FGS and CGS are not shown to significantly differ in their levels of concern with COVID-19, psychological well-being, or overall satisfaction with the university.

Tables 3 and 4 present the regression analysis results for three different models for the two samples, FGS and CGS. For both samples, Model 1 includes all key control variables, Model 2 adds the two background variables (Employed and Caregiving responsibilities), and Model 3 adds the variable of students' digital proficiency. In Model 1, satisfaction with university academic programs shows to be the strongest predictor for PWB, both for FGS $(\beta=0.426, p=0.000)$ and CGS $(\beta=0.389, p=0.000)$.

Table 4. Regression on psychological well-being (FGS).

\begin{tabular}{cccc}
\hline & FGS & \\
\hline & $\begin{array}{c}\text { Model 1 } \\
\text { (Control Only) }\end{array}$ & $\begin{array}{c}\text { Model 2 } \\
\text { (Without Digital } \\
\text { Proficiency) }\end{array}$ & $\begin{array}{c}\text { Model 3 } \\
\text { (Full Model) }\end{array}$ \\
\hline Age & 0.040 & 0.057 & 0.048 \\
\hline Gender & 0.015 & -0.010 & -0.009 \\
\hline Concern level with COVID-19 & -0.053 & -0.047 & -0.035 \\
\hline Satisfaction with university & $0.426^{* *}$ & $0.446^{* *}$ & $0.392^{* *}$ \\
\hline Employed & & $-0.148^{*}$ & $-0.154^{*}$ \\
\hline Caregiving responsibilities & & -0.026 & 0.004 \\
\hline Digital proficiency & $11.097^{* *}$ & $8.644^{* *}$ & $0.184^{* *}$ \\
\hline R-square (Adj R-square) & $0.187(0.170)$ & $0.214(0.190)$ & $0.244(0.216)$ \\
\hline F value & & & $8.715^{* *}$ \\
\hline
\end{tabular}

Note: Cell entries are standardized coefficients (ß). ${ }^{* *} p<0.01,{ }^{*} p<0.05$.

In Model 2, for both groups, students' overall satisfaction with university academic programs is positively related to their psychological well-being. Being employed shows to be significant for both samples, yet in opposite directions. For first-generation students, being employed is negatively related to their PWB $(B=-0.148, p=0.025)$, suggesting that being a full-time student (without any employment) is positively related to PWB for FGS. Interestingly, this is not the case for CGS: there is a positive, significant relationship between being employed and their PWB $(B=0.196, p=0.029)$. Overall, Model 2 shows to be a better model to predict PWB for CGS $(\mathrm{R}$ square $=0.255)$ than FGS $(\mathrm{R}$ square $=0.214)$, which is significant for both samples.

In Model 3, digital proficiency shows to be a significant predictor for both samples, and as hypothesized, positively relates to students' PWB. Yet, it is noted that digital proficiency is a more robust predictor for CGS $(B=0.322, p=0.000)$ than FGS $(\beta=0.184, p=0.007)$. Including students' digital proficiency improves the models for both samples, yet the model for CGS improves more noticeably $(\mathrm{R}$ square $=0.347)$ than FGS $(\mathrm{R}$ square $=0.244)$. 
Finally, to examine H3, we ran regressions on the whole sample (Table 5). Consistent with findings from previous regressions, students' satisfaction with university and digital proficiency are found to be the strongest predictors for their psychological well-being. Adding digital proficiency to the model increased R square from 0.192 (Model 1) to 0.236 (Model 2). Model 3 tests the moderating effect of FGS status on the relationship between digital proficiency and PWB, which does not show a significant result for the interaction term despite slight improvement of R square. FGS status itself does not predict students' psychological well-being when other variables are controlled. In combination with previous regressions, the results indicate that being a first-generation student per se does not lead to higher or lower psychological well-being necessarily. However, the results do show that the psychological well-being of FGS and CGS is driven by different factors in distinct ways.

Table 5. Regression on psychological well-being for the whole sample.

\begin{tabular}{cccc}
\hline & $\begin{array}{c}\text { Model 1 } \\
\text { (Control Only) }\end{array}$ & $\begin{array}{c}\text { Model 2 } \\
\text { (Digital } \\
\text { Proficiency) }\end{array}$ & $\begin{array}{c}\text { Model 3 } \\
\text { (Interaction) }\end{array}$ \\
\hline Age & 0.079 & 0.066 & 0.064 \\
\hline Gender & 0.012 & 0.012 & 0.012 \\
\hline Concern level with COVID-19 & -0.027 & -0.019 & -0.021 \\
\hline Satisfaction with university & $0.426^{* *}$ & $0.357^{* *}$ & $0.356^{* *}$ \\
\hline FGS or Non-FGS & 0.015 & 0.044 & 0.049 \\
\hline Employed & -0.029 & -0.033 & -0.031 \\
\hline Caregiving responsibilities & 0.018 & 0.049 & 0.047 \\
\hline Digital proficiency & & $0.226^{* *}$ & $0.293^{* *}$ \\
\hline FGS ${ }^{*}$ Digital proficiency & & & -0.079 \\
\hline R-square (Adj R-square) & $0.192(0.173)$ & $0.236(0.216)$ & $0.238(0.215)$ \\
\hline F value & $10.113^{* *}$ & $11.481^{* *}$ & $10.268^{* *}$ \\
\hline Note: Cell entries are standardized coefficients $(\mathbb{B}) .{ }^{* *} p<0.01{ }^{*} p<0.05$.
\end{tabular}

\section{Discussion}

The objectives of the study were to examine the role of digital proficiency in explaining the psychological well-being of college students, by focusing on first-generation students and their peers. Our data analysis shows the disparity in the digital proficiency between FGS and their peers along with the encouraging results that digital proficiency can exert a significant, positive effect on students' psychological well-being, regardless of their generational status.

The positive effect of digital proficiency in Blackboard and Zoom may be partly explained by the fact that students benefited from the interactive features on Blackboard and Zoom to enhance their class participation. In our study context of the online learning platforms, students interacted with Zoom for class meetings, performed class assignments on Blackboard, and participated in group discussions via Zoom breakout rooms or Blackboard discussion forums. For example, in their comments on their online learning experiences during COVID-19, students found the discussion forums on Blackboard helpful for sharing their views and developing a sense of belonging. They also appreciated the "raising hand" and "chat" functions on Zoom, which allowed the students in a class to provide immediate feedback simultaneously while engaging in a live conversation via video and audio.

The synchronicity benefits of computer-mediated communication can be classified as the two types of important technologies that promote well-being (Botella et al. 2012): eudaimonic technology (technology created to support engagement) and social/interpersonal technology (technology that provides social integration and connectedness between individuals and groups). As prior research on positive computing has suggested, the most 
common way to introduce well-being into the design principle is to design software that specifically supports and enhances personal experience (Riva et al. 2012). In the online learning environment, such digital proficiency allows students to better communicate and interact with their instructors and peers on Zoom and Blackboard, thus likely exerting a positive effect on students' psychological well-being.

Our data analysis shows mixed results regarding the competing hypotheses ( $\mathrm{H} 4 \mathrm{a}$ and $\mathrm{H} 4 \mathrm{~b}$ ) on the relationship between employment status (being employed) and psychological well-being. For CGS, being employed has a significant, positive effect on well-being, as we hypothesized in H4a. However, being employed shows a significant, negative effect on the well-being of FGS, as predicted in H4b. Similarly, our data analysis shows mixed results regarding the competing hypotheses ( $\mathrm{H} 5 \mathrm{a}$ and $\mathrm{H} 5 \mathrm{~b}$ ) on the relationship between caregiving responsibility and psychological well-being. For CGS, caregiving responsibility has a marginal, positive effect on well-being, as we hypothesized in H5a. However, our data analysis shows that caretaking responsibility has no significant effect on well-being, failing to support H5b. These mixed results for the two sub samples (CGS and FGS) may be explained by the socioeconomic and cultural background of FGS. Mostly coming from low-income households, FGS used to be employed to help their families meet financial needs and to take care of other family responsibilities while attending college. As Nunez and Cuccaro-Alamin (1998) identified, in addition to poor academic preparation, family responsibilities and full-time work became the two key barriers that obstructed the realization of FGS college goals. When FGS were managing demands from multiple fronts-employer, family, and college studies-the workload from employment may have caused them more psychological stress than benefits. Particularly during COVID-19, FGS were more likely to perform duties of essential work (e.g., delivery, grocery/retail stores), which would increase stress and affect well-being.

This study makes two theoretical contributions. First, our paper contributes to the emerging research of positive computing by empirically demonstrating the association between user competence with technology and psychological well-being, suggesting the importance of augmenting user skills in the context of online learning environments. Most technologies today are not yet "positively" designed: technology designers have not taken well-being into account (Gaggioli et al. 2017). When computer engineers design digital technologies for workplaces, they often consider measures like productivity, speed, and safety, as digital technologies are tools designed to improve work outcomes and performance. However, researchers of positive computing argue that information and communication technologies such as social networking platforms can be used to improve the quality of personal experiences through three mechanisms-affective quality, engagement, actualization, and connectedness (Riva et al. 2012). Our study presents empirical evidence to show the positive effect of user proficiency in ICT on users' psychological well-being, suggesting the importance of incorporating positive computing in student success in online education.

Second, our study extends the research on first-generation college students by demonstrating the increasingly important role that students' technical capital plays, as compared to prior FGS research that has paid more attention to students' familial capital and community resources. Compared to FGS in prior studies conducted with student samples in the 1990s and early 2000 (i.e., Engle and Tinto 2008; Nunez and Cuccaro-Alamin 1998), FGS in the 2010s and today have more exposure to technical resources. Some of the FGS belong to Generation Z (born between 1993 and 2005) who grew up in the WiFi and smartphone environment (Turner 2015), while some FGS are non-traditional students who have employment experience and may have prior exposure to technology in the workplace. With increasing college instructions offered online, the digital proficiency of FGS should be cultivated earlier, prior to or at the beginning of their college journey to improve their college success.

Practically, our findings suggest that developing and strengthening college students' digital proficiency is especially important for promoting their psychological well-being in the time of the COVID-19 pandemic when delivery of face-to-face instruction and 
physical classroom interactions are diminished. Under this circumstance, the level of students' digital proficiency explains a student's psychological well-being in a significant and positive direction. This effect is especially larger for FGS who are often from an underserved student population, pointing to the importance of extra effort in supporting FGS in their IT capability. As digital proficiency is mostly included in program assessment of student learning, our results suggest that the assessment in this learning outcome may need to account for the generational status of the students (i.e., FGS and CGS) to understand any gap and make progress to "close the loop." In the long run, technology readiness and proficiency in using online education platforms are essential to student academic success in higher education, regardless of the modality of a course. A more instituted monitoring and utilizing of students' well-being in higher education institutions is beneficial (Diener and Ryan 2009).

Contributions notwithstanding, it is important for us to note the potential limitations of the study. First, the findings of this study are potentially limited by the location of the research site and by the sample size. Second, as our data is cross-sectional, future research with a more rigorous design should further examine the causality between digital proficiency and psychological well-being by using longitudinal data. Another promising avenue for future research is to examine the mechanisms through which digital proficiency explains psychological well-being. Finally, how non-traditional, adult students employ their agency and determination to persist in their online learning is worth further investigation (Merrill 2015).

\section{Conclusions}

The coronavirus pandemic has disrupted the normal operations of organizations, from educational institutions to businesses, giving rise to a new normalcy for online learning. Online learning is likely to become an integral part of our educational programs and business practices in the long run. For example, when colleges plan for the 2021-2022 academic year, they are embracing the hybrid (online and face-to-face) learning modality as an important component of their planning. Prior research on individual use of ICT has suggested that users' computer self-efficacy increases ICT usage and reduces computer anxiety (Fagan et al. 2004). Focusing on the online learning environment, our study introduces an important concept-the quality of personal ICT experiences-that consists of three key components of affective quality, engagement, and connectedness. These components are worth further exploration as higher education institutions seek to further connect to students' academic success during these trying times. We thus call for further research and advancement in accounting for the quality of student academic experience and well-being in the design and development of technologies in higher education.

Our study has provided evidence to show the positive effect of technology proficiency on adult learners' psychological well-being. This finding is consistent with prior research on positive computing, which posits that ICT can be used to improve the quality of personal and interpersonal through the mechanisms-connectedness and engagement/actualization (Riva et al. 2012). Moreover, our study shows that digital proficiency has a significant effect on enhancing the well-being of FGS as well as of their peers. Thus, our study suggests that for educational institutions to promote student academic performance and psychological well-being, it is important to develop and implement technology training programs and education policies to improve their technical competency and proficiency with ICT in both the online learning and in-person learning environments. Moreover, more attention and resources should be directed to underserved students such as first-generation college students because this vulnerable student population face more challenges in effectively navigating college environments (Schwartz et al. 2018) and persisting in college (Lohfink and Paulsen 2005).

Our study has made an initial effort in bringing more awareness to the psychological well-being of the vulnerable student population of FGS - those who strive to achieve higher academic goals than their high school-educated parents. We hope that the digital 
proficiency-PWB relationship has offered some useful insights into improving online learning and the psychological well-being of first-generation college students. Future studies in a remote work context will offer us further insights into empowering individuals from diverse economic and ethnic backgrounds in times of crisis.

Author Contributions: Conceptualization, X.D. and Z.Y.; methodology, X.D. and Z.Y.; software, Z.Y.; validation, X.D. and Z.Y.; formal analysis, Z.Y. and X.D.; investigation, X.D. and Z.Y.; resources, X.D.; data curation, Z.Y. and X.D.; writing - original draft preparation, X.D. and Z.Y.; writingreview and editing, X.D. and Z.Y.; visualization, Z.Y.; supervision, X.D.; project administration, X.D.; funding acquisition, Not Applicable. All authors have read and agreed to the published version of the manuscript.

Funding: This research received no external funding.

Institutional Review Board Statement: The study was conducted according to the guidelines of the Human Subject Committee and approved by the Institutional Review Board of California State University Dominguez Hills (protocol code 17-172 and date of approval: 17 March 2020).

Informed Consent Statement: Informed consent was obtained from all subjects involved in the study.

Data Availability Statement: The data are not publicly available due to confidentiality protection for study participants.

Conflicts of Interest: The authors declare no conflict of interest.

\section{References}

Appana, Subhashni. 2008. A review of benefits and limitations of online learning in the context of the student, the instructor and the tenured faculty. International Journal on E-Learning 7: 5-22.

Bewick, Bridgette, Gina Koutsopoulou, Jeremy Miles, Esther Slaa, and Michael Barkham. 2010. Changes in undergraduate students' psychological well-being as they progress through university. Studies in Higher Education 35: 633-45. [CrossRef]

Botella, Cristina, Giuseppe Riva, Andrea Gaggioli, Brenda K. Wiederhold, Mariano Alcaniz, and Rosa M. Banos. 2012. The present and future of positive technologies. Cyberpsychology, Behavior, and Social Networking 15: 78-84. [CrossRef]

Burrus, Jeremy, Diane Elliott, Meghan Brenneman, Ross Markle, Lauren Carney, Gabrielle Moore, Anthony Betancourt, Teresa Jackson, Steve Robbins, and Patrick Kyllonen. 2013. Putting and keeping students on track: Toward a comprehensive model of college persistence and goal attainment. ETS Research Report Series 2013: i-61. [CrossRef]

Calvo, Rafael A., and Dorian Peters. 2014. Positive Computing: Technology for Wellbeing and Human Potential. Cambridge: MIT Press.

Calvo, Rafael A., and Dorian Peters. 2015. Introduction to positive computing: Technology that fosters wellbeing. Paper Presented at 33rd Annual ACM Conference Extended Abstracts on Human Factors in Computing Systems, Seoul, Korea, April 18-23; pp. 2499-500.

CDC. 2020. COVID-19 in Racial and Ethnic Minority Groups. Centers for Disease Control and Prevention. May 8. Available online: https:/ / www.cdc.gov/coronavirus/2019-ncov/need-extra-precautions/racial-ethnic-minorities.html (accessed on 20 May 2020).

Chaney, Sarah, and Eric Morath. 2020. April Unemployment Rate Rose to a Record 14.7\%. The Wall Street Journal, May 8. Available online: https:/ / www.wsj.com/articles/april-jobs-report-coronavirus-2020-11588888089 (accessed on 24 April 2020).

Chen, Hsuan-Ting, and Xueqing Li. 2017. The contribution of mobile social media to social capital and psychological well-being: Examining the role of communicative use, friending and self-disclosure. Computers in Human Behavior 75: 958-65. [CrossRef]

Chen, Xianglei, and C. Dennis Carroll. 2005. First-Generation Students in Postsecondary Education: A Look at Their College Transcripts. Postsecondary Education Descriptive Analysis Report. NCES 2005-171. Washington, DC: National Center for Education Statistics, U.S. Education of Department.

Clark, Andrew. E. 2010. Work, Jobs, and Well-Being Across the Millennium. International Differences in Well-Being 436-68. Available online: https:/ / halshs.archives-ouvertes.fr/halshs-00566139 (accessed on 30 April 2020).

Coe, Erica Hutchins, and Kana Enomoto. 2020. Returning to Resilience: The Impact of COVID-19 on Mental Health and Substance Use. McKinsey \& Company Website, April 2. Available online: https://www.mckinsey.com/industries/healthcare-systems-andservices/our-insights / returning-to-resilience-the-impact-of-covid-19-on-behavioral-health\# (accessed on 2 May 2020).

Creed, Peter A., Jessica French, and Michelle Hood. 2015. Working while studying at university: The relationship between work benefits and demands and engagement and well-being. Journal of Vocational Behavior 86: 48-57. [CrossRef]

Diener, Ed, and Katherine Ryan. 2009. Subjective well-being: A general overview. South African Journal of Psychology 39: 391-406. [CrossRef]

Drinkwater, Michael J., Deanne Gannaway, Karen Sheppard, Matthew J. Davis, Margaret J. Wegener, Warwick P. Bowen, and Joel F. Corney. 2014. Managing active learning processes in large first year physics classes: The advantages of an integrated approach. Teaching and Learning Inquiry 2: 75-90. [CrossRef]

Dumais, Susan A., and Aaryn Ward. 2010. Cultural capital and first-generation college success. Poetics 38: 245-65. [CrossRef] 
Emadpoor, Leila, Masoud Gholami Lavasani, and Seyyed Mahdi Shahcheraghi. 2016. Relationship between perceived social support and psychological well-being among students based on mediating role of academic motivation. International Journal of Mental Health and Addiction 14: 284-90. [CrossRef]

Engle, Jennifer, and Vincent Tinto. 2008. Moving beyond Access: College Success for Low-Income, First-Generation Students. Washington, DC: Pell Institute for the Study of Opportunity in Higher Education.

Everett, Michele C. 2017. Fostering first-year students' engagement and well-being through visual narratives. Studies in Higher Education 42: 623-35. [CrossRef]

Fagan, Mary Helen, Stern Neill, and Barbara Ross Wooldridge. 2004. An empirical investigation into the relationship between computer self-efficacy, anxiety, experience, support and usage. Journal of Computer Information Systems 44: 95-104.

Gaggioli, Andrea, Giuseppe Riva, Dorian Peters, and Rafael A. Calvo. 2017. Positive technology, computing, and design: Shaping a future in which technology promotes psychological well-being. In Emotions and Affect in Human Factors and Human-Computer Interaction. Philadelphia: Elsevier Inc., pp. 477-502.

Garriott, Patton O., and Stephanie Nisle. 2018. Stress, coping, and perceived academic goal progress in first-generation college students: The role of institutional supports. Journal of Diversity in Higher Education 11: 436. [CrossRef]

Gui, Marco, Marco Fasoli, and Roberto Carradore. 2017. "Digital well-being". Developing a new theoretical tool for media literacy research. Italian Journal of Sociology of Education 9: 155-73.

Hung, Hui-Chun, Shelley Shwu-Ching Young, and Chiu-Pin Lin. 2015. No student left behind: A collaborative and competitive game-based learning environment to reduce the achievement gap of EFL students in Taiwan. Technology, Pedagogy and Education 24: 35-49. [CrossRef]

Johnson, Genevieve M., Andrew J. Howell, and Jillianne R. Code. 2005. Online discussion and college student learning: Toward a model of influence. Technology, Pedagogy and Education 14: 61-76. [CrossRef]

Khan, Arshia, Ona Egbue, Brooke Palkie, and Janna Madden. 2017. Active learning: Engaging students to maximize learning in an online course. Electronic Journal of E-Learning 15: 107-15.

Kohler Giancola, Jennifer, Matthew J. Grawitch, and Dana Borchert. 2009. Dealing with the stress of college: A model for adult students. Adult Education Quarterly 59: 246-63. [CrossRef]

Livingstone, Sonia, and Ellen Helsper. 2007. Gradations in digital inclusion: Children, young people and the digital divide. New Media E Society 9: 671-96.

Lohfink, Mandy Martin, and Michael B. Paulsen. 2005. Comparing the determinants of persistence for first-generation and continuinggeneration students. Journal of College Student Development 46: 409-28. [CrossRef]

Merrill, Barbara. 2015. Determined to stay or determined to leave? A tale of learner identities, biographies and adult students in higher education. Studies in Higher Education 40: 1859-71. [CrossRef]

$\mathrm{Na}$, Sumin, Lisa B. Spanierman, and Christopher E. Lalonde. 2017. Exploring moderators to understand the association between vertical collectivism and psychological well-being among Asian Canadian students. Journal of Diversity in Higher Education 10: 288. [CrossRef]

$\mathrm{Ng}$, Wan. 2012. Can we teach digital natives digital literacy? Computers E Education 59: 1065-78.

Nunez, Anne-Marie, and Stephanie Cuccaro-Alamin. 1998. First-Generation Students: Undergraduates Whose Parents Never Enrolled in Postsecondary Education. Statistical Analysis Report, Postsecondary Education Descriptive Analysis Reports. Washington, DC: National Center for Education Statistics (NCES), U.S. Department of Education.

Peters, Dorian, Rafael A. Calvo, and Richard M. Ryan. 2018. Designing for motivation, engagement and wellbeing in digital experience. Frontiers in Psychology 9: 797. [CrossRef]

Redford, Jeremy, and Kathleen Mulvaney Hoyer. 2017. First Generation and Continuing-Generation College Students: A Comparison of High School and Postsecondary Experiences. Statistics in Brief. Washington, DC: National Center for Education Statistics (NCES), U.S. Department of Education.

Riva, Giuseppe, Rosa M. Baños, Cristina Botella, Brenda K. Wiederhold, and Andrea Gaggioli. 2012. Positive technology: Using interactive technologies to promote positive functioning. Cyberpsychology, Behavior, and Social Networking 15: 69-77. [CrossRef]

Ryan, Richard M., and Edward L. Deci. 2000. Self-determination theory and the facilitation of intrinsic motivation, social development, and well-being. American Psychologist 55: 68. [CrossRef]

Ryff, Carol D. 1989. In the eye of the beholder: Views of psychological well-being among middle-aged and older adults. Psychology and Aging 4: 195. [CrossRef]

Schwartz, Sarah E. O., Stella S. Kanchewa, Jean E. Rhodes, Grace Gowdy, Abigail M. Stark, John Paul Horn, McKenna Parnes, and Renée Spencer. 2018. “I'm Having a Little Struggle with This, Can You Help Me Out?": Examining Impacts and Processes of a Social Capital Intervention for First-Generation College Students. American Journal of Community Psychology 61: 166-78. [CrossRef]

Shopova, Tatiana. 2014. Digital literacy of students and its improvement at the university. Journal on Efficiency and Responsibility in Education and Science 7: 26-32. [CrossRef]

Tang, Chun Meng, and Lee Yen Chaw. 2016. Digital literacy: A prerequisite for effective learning in a blended learning environment? Electronic Journal of E-Learning 14: 54-65.

Ting, Yu-Liang. 2015. Tapping into students' digital literacy and designing negotiated learning to promote learner autonomy. The Internet and Higher Education 26: 25-32. [CrossRef]

Turner, Anthony. 2015. Generation Z: Technology and social interest. The Journal of Individual Psychology 71: 103-13. [CrossRef] 
Van den Eijnden, Regina J. J. M., Gert-Jan Meerkerk, Ad A. Vermulst, Renske Spijkerman, and Rutger C. M. E. Engels. 2008. Online communication, compulsive Internet use, and psychosocial well-being among adolescents: A longitudinal study. Developmental Psychology 44: 655. [CrossRef] [PubMed]

WHO. 2020. WHO Director-General's Opening Remarks at the Media Briefing on COVID-19. Available online: https://tinyurl.com/ vyvm6ob (accessed on 1 April 2020).

Yang, Zheng. 2021. Understanding spontaneous volunteering in crisis: Towards a needs-based approach of explanation. The Social Science Journal. [CrossRef] 